\title{
Ausencia y presencia de Dios: Diez estudios fenomenológicos*
}

Absence and presence of God: ten phenomenological studies

Ausência e presença de Deus: Dez estudos fenomenológicos

Fecha de entrega: 24 de agosto de 2013

Fecha de aprobación: 20 de diciembre de 2013

Orlando Escobar ${ }^{* *}$

Entendida como "la manera de vivir la historia, en cierto modo como condena o como fatalidad", la fe ha sido recibida. Y esta ha sido transmitida en términos como en los que se sostiene que la filosofía debe aprenderse en Europa o Norteamérica, que nuestra economía es dependiente y que la piel y sangre que llevamos es impura. Para Vargas Guillén, la tragedia de nuestra historia se explica en parte por una educación patriarcalista que entrena solo para obedecer. Por esta razón, su propuesta en este libro es la de una deconstrucción fenomenológica del patriarcalismo que conduce a la superación de la economía del don en busca del sentido del amor "como proyecto y desenvolvimiento del ser", lo cual es posible si se da el paso del estudio del fenómeno religioso al estudio de Dios como fenómeno. Como ejemplo para dar dicho paso, el autor retoma un texto del escritor Juan Rulfo, Talpa, publicado en 1950. Se trata, según él, "de la acción pasiva de la culpa; esta ha sido creada mediante mecanismos de autoridad y se ha entronizado por vía de la experiencia religiosa”.

\footnotetext{
* Vargas Guillén, G. (2011). Ausencia y presencia de Dios: Diez estudios fenomenológicos. Bogotá: San Pablo. 242 p. ISBN 9789587157406

* Doctorando en filosofía de la Universidad Santo Tomás.
} 
Estudio I, "Excedencia y saturación: Fenomenología de la ausencia y la presencia de Dios". Excedencia es un término de la fenomenología de P. Ricœur y saturación de la de Marion y ambos equivalen a decir Dios. Un fenómeno saturado "es aquel en el cual la constitución de su sentido es despliegue de las potencias anímicas dadoras". La excedencia (de sentido), por su parte, "es una operación constitutiva de sentido a partir de lo dado, pero en el orden del despliegue de nuevos horizontes de entendimiento y de compresión". En otras palabras, es una hermenéutica.

Estudio II, "De la ontoteología a Dios-como-fenómeno". Aquí el autor se propone discutir la acusación de Heidegger de que toda la metafísica occidental es onto-teología. Para Vargas Guillén "hay una fenomenología del fenómeno-Dios o de Dioscomo fenómeno". No interesa tanto si tal fenómeno Dios es una realidad, un ente, un dato o un "qué" cuanto que la experiencia humana exige la idea de Dios. Es la misma existencia humana "[...] la que exige razones fundadas para hablar desde la experiencia de Dios en nuestras vidas, esto es, en tanto fenómeno".

Estudio III, “El don: Fenomenología de la doble implicación sujeto-don”. Desde que el autor fue invitado a comentar el libro Mendigos de ayer y hoy, de Amalia Quevedo, y teniendo en cuenta su formación franciscana, comenzó a "sistematizar" su reflexión sobre el tema del don, que "[...] entrelaza tanto un punto de vista sobre la limosna y sobre la donación como sobre el donatario y sobre el donador". Don y limosna, unidas por la caridad, "[...] son las maneras como se puede hacer una resistencia pacífica al capitalismo". En la primera parte de este tercer estudio, Vargas Guillén desarrolla los presupuestos de una conversación sobre el don, a partir del planteamiento de J. Derrida. En la segunda parte del "método" del "contrapunto" para avanzar en la conversación con Quevedo.

Estudio IV, "Memoria y archivo: Entre fenomenología y hermenéutica". En la tradición fenomenológica hay, al parecer, dos formas de afrontar la relación con el archivo, la deconstructiva, presentada por J. Derrida, y la hermenéutica, ofrecida por P. Ricœur. Para Vargas Guillén no se puede analizar el archivo como asunto de la fenomenología sin tener en cuenta el lenguaje -incluyendo aquí la escritura, la lectura y el habla- y la historia. Concluye: "[m]emoria sí, pero con la posibilidad de historia. Narración sí, pero como apertura de multiplicidad de sentidos y de horizontes del ser. Repetición, en fin, sí, pero orientada a la diferencia, al diferendo, a lo otro, a la alteridad". 
Estudio V, "La deconstrucción fenomenológica del patriarcalismo como política de la memoria". La más importante tarea de la filosofía en Colombia es ayudar a superar el patriarcalismo, responsable del autoritarismo. Se requiere un "sujeto fuerte" que defienda sus derechos y promueva la solidaridad y la justicia. El estudio sigue un proceso de fenomenología genética, primero reconstructivo, siguiendo a Habermas, posteriormente deconstructivo, siguiendo a $\mathrm{H}$. Broch. El silencio del apa con el holocausto judío, insinuado por una carta de Edith Stein a Pío XI, ilustra un modelo de crítica al tradicional patriarcalismo de la Iglesia Católica.

Estudio VI, "Los límites de la rebeldía. La fenomenología de Albert Camus: su lectura y su herencia". Camus puede ser considerado "lector y crítico de la fenomenología" de Husserl. Así lo demuestra en la frecuencia con que cita a Husserl en El mito de Sísifo: Ensayo sobre el absurdo. Vargas Guillén quiere demostrar que, en dicho ensayo, "Camus transforma la categoría subjetividad trascendental de la fenomenología -de la fenomenología husserliana- en rebeldía; que en cuanto la halla, la pone en relación con el absurdo como estructura de desenvolvimiento que da con la libertad y la pasión como sus formas de despliegue".

Estudio VII, "La fenomenología y el ideal de la ciencia. En el centenario del artículo: La filosofía, ciencia rigurosa”. Para Vargas Guillén, la diferencia entre Husserl y Heidegger radica en que el primero concibe la filosofía como ciencia mientras el segundo rechaza dicha pretensión. Este estudio toma posición ante tales posturas y evalúa la posibilidad de la filosofía como ciencia que renuncia a su pretensión científica. Para llevar cabo dicho objetivo da tres pasos: 1) establecer lo que significa ciencia y más concretamente ciencia rigurosa en Husserl; 2) explicar el sentido en que la fenomenología es psicología; y 3) “[... sistematizar el sentido en que la ciencia funda la formación como proyecto" de la humanidad.

Estudio VIII, “Mundo de la vida y fenomenología del lugar". Cosa y espacio es una de las obras más importantes de Husserl al tratar el tema de la percepción, toda vez que él hace allí una descripción de las estructuras de esta. En el ámbito de la percepción se constituye la facticidad en el espacio, cuyo "punto cero" es el cuerpo que, al permanecer quieto o al moverse, no solo "promueve la facticidad a sentido" sino que se "espacializa, esto es, constituye el lugar.

Dos estudios complementarios, "Las ruinas de Éfeso, Jonia" y "Tematización de la metafísica en el Parménides de Platón" completan los diez estudios del nuevo libro 
del profesor Germán Vargas Guillén Ausencia y presencia de Dios. Diez estudios fenomenológicos.

No hay duda del carácter fenomenológico de estos estudios, pero en algunos no es tan clara la relación entre el contenido de algunos de los mismos con el título que se le ha dado al libro Ausencia y presencia de Dios. Esperamos el momento en que un tema de tanta trascendencia pueda desarrollarse exclusivamente, es decir que el fenomenólogo pueda usar toda su habilidad para describir el "fenómeno" de dicha ausencia o de dicha presencia. Podríamos de esta manera ir dando pasos hacia algo todavía no menos real ni existencial como la mística en la que dicha presencia de Dios está necesariamente antecedida de una espesa niebla (ausencia), de una "noche oscura", de un gran misterio, de una gran soledad, condiciones para la presencia real y transformante del ser humano ante la fascinación del misterio de Dios.

Por otra parte, no parece tampoco tan claro que lo planteado en la introducción del libro, en el sentido de que una de las principales funciones de la filosofía en Colombia es ayudar a superar el patriarcalismo cultural que nos caracteriza, se aborde explícitamente en dichos estudios. Considero que Vargas Guillén ha dejado planteada una tesis que requiere desarrollo. Aguardamos el momento en que el autor se detendrá a fenomenologizar sobre dicha realidad para darnos los criterios que los amantes de la filosofía deseamos para hacer de ella un ejercicio transformante de la realidad. 